\title{
Evolution and Value of Design
}

\author{
Lu Yongxiang
}

Chinese Academy of Sciences 100864, China

\section{Introduction}

Design is creative ideas, plans, and calculations of people for equipment manufacturing, engineering construction, business management, and service innovation; it is an invention that transforms and integrates information and technology knowledge into a complete solution and valuable products; it is the precursor, preparation, and key link of the targeted innovative practice. Design determines the direction, goals, and path, as well as the value of innovation. Design innovation leads the impetus of the civilization of human society progress, the knowledge and technology, value ideas, talent teams, as well as the mode and environment of design develops with the human civilization evolution. In the Paleolithic Age, our ancestors had already tried to make original tools with natural materials. During the Neolithic Age, the emergence of pottery marked the beginning of human design with a clear goal. Since the agricultural age, human society can be roughly divided into agricultural age, industrial age, and knowledge network age; design presents different characteristics at the same time.

\section{Evolution of design}

For thousands of years with agriculture, people obtained natural resources by planting, grazing, fishing and hunting, through training of experience skills, by using labor force, livestock, water and wind as natural energy, by using dirt and rocks, plants and animals, copper and iron as materials, transported by walking, sedan chair, carriage or boat, communicated by beacon towers, messengers or sending mails, designed and made stoneware, pottery, silk, hemp, cotton, costumes, ritual items, swords and armours, architecture and furniture. With such elements, people have created the glorious agricultural culture. That was the 1.0 era of design, which can also be called "traditional design." China led the world with its "four great inventions" and designs of pottery, silk, furniture, and architecture.

Less than three hundred years since the industrial age, people designed and created power machinery and engineering equipment, exploited mineral resources, depended on the capital, technology, equipment, and labor resources by producing and using iron and steel, non-ferrous metals, polymer materials, inorganic materials, and semiconductor functional materials with fossil energy and nuclear energy. People also invented vehicles, such as steam engines, internal combustion engines, electric cars, trains, ships, and airplanes, as well as many kinds of communication media including telephone and telegraph, digital communication, global positioning system/geographic information system (GPS/GIS), optical cable/cellular telephone, and the Internet. The products, technology and equipment, and engineering design led and promoted the production mode that has characteristics of mechanization, electrification, mechatronics, and digitization. The modern design in the industrial age comprises the 2.0 era of design. The United States and industrial countries of Europe have been playing a leading role in it. In the 20 's and 30's of the twentieth century, the Bauhaus-Universitaet Weimar defended the unity between art and technique, which indicated that, although design should serve humanity, the product should follow natural and objective laws. The industrial design, capable of meeting the requirements of industrial development and massive production, used to have far-reaching effects on architectural and industrial esthetic design.

In the 21 st century, the humanity enters an era of knowledge and networking. People are increasingly relying on scientific and technological progress, creative ideas, and innovative development; and will rely more on clean renewable energy, designing the Internet, Internet of things, smart grid, and traffic logistics

Received date: April 20, 2017; Revised date: May 15, 2017

Corresponding author: Lu Yongxiang, Chinese Academy of Sciences, Academician; Chinese Academy of Engineering, Academician; Former President of Chinese Academy of Sciences; Vice Chairman of the Standing Committee of the tenth and eleventh National People's Congress

funding program: CAE Advisory Project “Research on Design Competitiveness" (2015-XZ-13).

Chinese version: Strategic Study of CAE 2017, 19 (3): 001-005

Cited item: Lu Yongxiang. Evolution and Value of Design. Strategic Study of CAE, https://doi.org/10.15302/J-SSCAE-2017.03.010 
network, which are more secure, convenient, efficient, and intelligent, designing and creating environmental intelligent materials, superstructure functional materials, degradable materials, and renewable materials, as well as developing collaborative intelligent design, manufacturing, and service based on networking and big data. The design that depends on network creative production now enters a new stage, the 3.0 era of design. IBM, Intel, MS, Oracle, Apple, Facebook, and Google lead the innovative development of integrated circuit (IC), software, network platforms, and information and communication technology (ICT).

While "design 1.0" led and promoted the agricultural civilization and "design 2.0" led and promoted the world's First and the Second Industrial Revolutions, "design 3.0" will certainly result in a new industrial revolution that features green and low carbon, network intelligence, integrated innovation, cooperation, and sharing. It can also lead to a new trend of civilization with sustainable development. The evolution of design is shown in Fig. 1.

\subsection{The evolution of knowledge and connotation of design}

Design 1.0 of the agricultural age was based on teaching, training, and innovation by individuals, families or manufactures; it emphasized in showing the function, structure, culture, and art, which had obvious regional and national cultural characteristics. Design 2.0 of the industrial age was based on innovation and application of modern technology, arts, and humanities; it was developed by talent training at school, and was pushed forward by competitive environments and social demand, starting the globalization process. As the era of knowledge and networking, "design 3.0" is based on the knowledge innovation of technology, economics, society, culture, and ecology, as well as big data information. Besides basic education in schools, global networking becomes a super platform of spreading and sharing knowledge and information, collaborative innovation, competition, and cooperation, which fully reflects integrated innovation of substance, knowledge, information, computer, culture and skills. It also shows user-centered value creation, and creating and sharing individuation, diversification, and globalization.

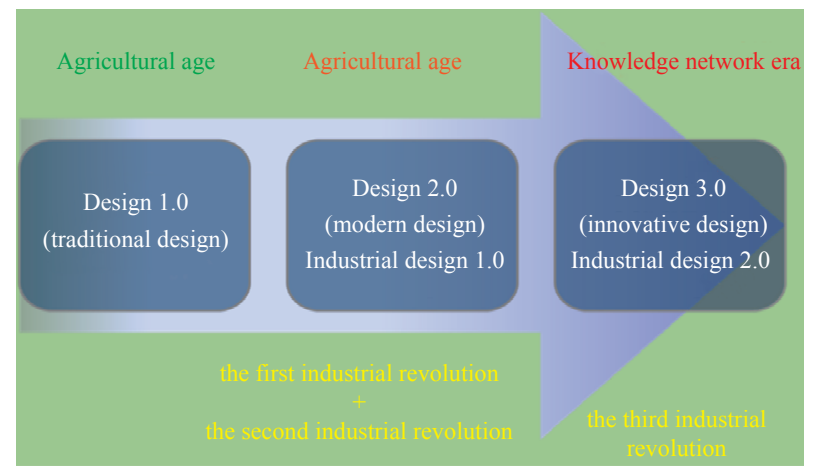

Fig. 1. Evolution of design.

\subsection{Evolution of the relation between design and manufacture service}

Design and manufacture services in the agricultural age were primitively mixed, applied by individuals, families and manual workshops, and limited by the skills of the craftsmen and the natural materials and tools available. Design gradually separated from manufacture services in the industrial age when the occupation of designer was first recognized. Thanks to the knowledge innovation, material diversity, manufacturing technology, and equipment innovation, as well as the market competition, design and manufacture services developed harmoniously and rapidly. In the age of knowledge network, design mixes with manufacture services again; however, design plays a leading role this time. With the development and innovation of numerical control machines, 3D printing, and digital network intelligent manufacturing of subtractive or additional materials, anything we design can be manufactured. Thus, innovative design will be demonstrated more freely.

\subsection{Evolution of the design team}

In the agricultural age, the handcrafted craftsmen acted both as a producer and as a designer. The design was limited by personal knowledge, family, and workshop capacity. The industrial age is an era of factorization, marketization, and mass production; at that moment, design and manufacturing played a cooperative role, and so emerged professional designers and teams. As a result, designers separated from engineers, craftsmen, technical workers, managers, and customers. However, in the age of knowledge network, every person can participate in innovative creation, initiation, and innovative design; designers, manufacturers, managers, servers, and costumers innovate collaboratively, and creative ideas constantly spring up. It is a new era of personalized, customized, and Internet supported collaborative design, which depends on users' needs.

\subsection{Evolution of the value concept of design}

In the agricultural age, the value of design was mainly reflected in the applied value of the product, in social ethics, and in cultural and artistic values. The simple, delicate Chinese furniture and the famous Hui style architecture, which is present in the architectural complex of the Forbidden City and started to appear in Ming and Qing dynasties, reflect China's social and cultural values in the agricultural age. Because of low productivity, humans have adapted to nature in general. Design in industrial age depended on the innovation of modern scientific knowledge and technology, generated new functions and values through creative ideas, designed and created new processes and equipment, created higher economic and brand values, led the modern consuming culture and fashion, and, at the same time, 
created new ways of business services. The scale development of industry resulted in the lack of non-renewable natural resources and ecological environment pollution. In the age of knowledge network, based on the innovation of knowledge technology and the concept of culture, innovative design will accelerate the evolution of human lifestyle and civilization, returning to the harmonious and coordinated development of economic, social, and ecological environment and leading the impetus of human society to create a win-win, equitable, and harmonious sustainable development.

\subsection{Change of approaches and environment in design}

In the industrial age, design was based on science, technology physics, marketing environment, and culture. It has highly developed in many fields, such as mechanical design, mechatronic design, mechanical and electronic integration design, technological design, industrial design, engineering and managing design, marketing and service design, IC/MEMS design, software design, and $\mathrm{CAD} / \mathrm{CDS} / \mathrm{CAE}$ and other design tools. In the age of knowledge network, the process and method of design, the object of design, and its manufacturing process, as well as the operating services, are based on the global cyber-physical-network computing environment and on big data, integrating global resources and creativities online. Design will pay more attention to user experience and value creating. Design innovation will extend to intelligent terminal products/ intelligent system design, network-mutual design, personalized and customized design, $3 \mathrm{D}+\mathrm{X}-$ virtual reality/ mixed reality (VR/MR) design, artificial intelligence design, and cloud platform and industrial ecological design.

\section{The value and significance of innovative design}

Design is the pioneer and starting point for innovation, creation, and manufacturing services. It is also an independent integration of creative ideas, thoughts, and plans. It is the key to the sustainable development and innovation leading abilities of the national innovative enterprises in the global market (Fig. 2). Its key part and foundation is innovative people, whose value concept, knowledge, technology, creative ability, with the addition of their innovation environment, system and mechanism, constitute the competitive elements of innovation design (Fig. 3).

\subsection{Leading the improvement of manufacturing service quality}

Mercedes-Benz has won global credit by adhering to a high-quality design concept and a strict and exquisite manufacturing technology that is safe, reliable, comfortable, and satisfying for the passenger. It has become a century's classic in world's high-end brand cars. HuaWei broke through the core

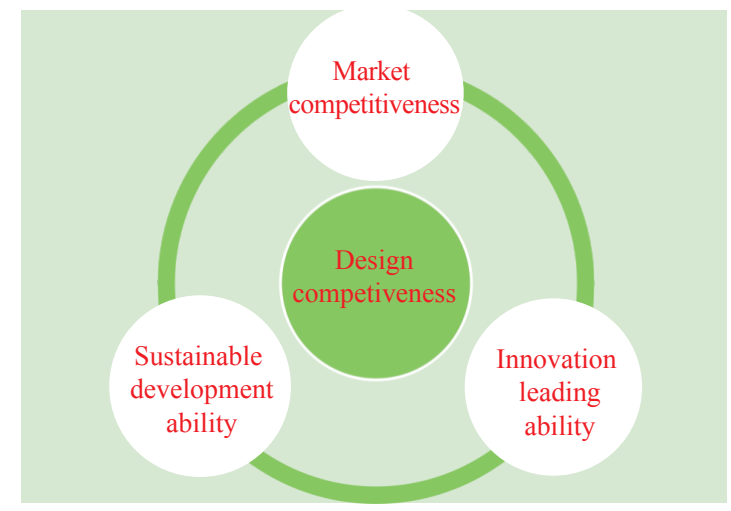

Fig. 2. Innovative design competiveness.

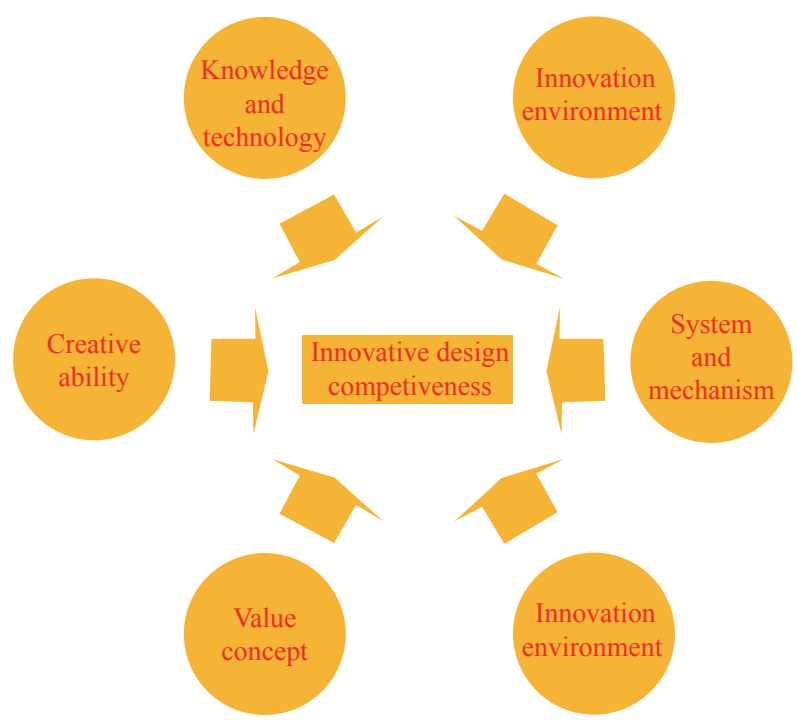

Fig. 3. Competitive elements of innovation design.

technology of chip, algorithm, and software, integrated global high-end design such as Leica and Porsche, and committed to provide customers with better, high-quality smartphones. Therefore, the brand competitiveness and market value are rising rapidly.

\subsection{Creating new experience and value for customers}

BMW has won the competitive advantage by pursuing strong driving power and superior driving experience with high quality, performance, and technology, which are considered the bases of design. The design of mobile phones popular among young users, such as OPPO and VIVO, aims to achieve better quality and experience in photography, selfie, music, and fast charge, standing out in the competition both in the domestic and foreign markets.

\subsection{New technology and equipment of innovative design}

Design can achieve substantial improvements in quality and 
efficiency, energy saving and emission reducing, and even drive an industrial revolution. In 1952, the Voest Alpine company in Austria devised the technology and equipment of oxygen blown converter steelmaking that replaced the open-hearth furnace and shorted the steelmaking time from eight to ten hours to eight to ten minutes, as well as achieved smelting with negative energy consumption. In the 1950s, the Pilkington company in UK devised the technology and equipment of float glass process, which brought a revolution in quality efficiency of flat glass production. On the basis of introduction, digestion, and absorption, Jiangsu Hengtong Optoelectronic Co., Ltd. independently designed and developed the $200 \mathrm{~mm}$-diameter, $6 \mathrm{~m}$-long optical fiber preform rod that is the core technology and advanced equipment in optical fiber and cable, becoming the world's top optical fiber and cable supplier.

\subsection{Designing and creating new products, applications and platforms}

Design can develop new markets and create industrial ecology. Shenzhen Dajiang innovatively integrated the high-performance photography platform, flight control system software, wireless transmission, modular design, and Internet marketing, as well as designed and created an unmanned aerial photography vehicle that has 70 percent of the global market. Google and Baidu not only are the world's most powerful search engines but also constantly design and launch new applications and platforms for navigation maps, free encyclopedias, language processing, and image identification. They create a new industrial ecology by collectively inventing and sharing knowledge, information, and service.

\subsection{Green design}

Design can lead and promote the efficient use of clean and recyclable resources, which reflects the ecological environmental value of design. By innovating and creating environment-friendly materials, products, technology, clean renewable energy, low-carbon intelligent transportation and logistics, green energy-saving buildings, and low-carbon communities and cities, it will promote sustainable development between human and nature from the source, leading green and low-carbon production and the supply-side lifestyle.

\subsection{Creation of brand and cultural value}

The design of Italian and French clothing, leather, perfume, and cosmetics not only create many world-famous high-end brands, but also lead the global fashion consumption culture.

\subsection{Design creates a new type of business}

Design can create new advantages and values of traditional industries. Zhengzhou Xindafang Heavy Industry Technology Co., Ltd. designed and created a large special delivery construction equipment with a mechanics-electronics-hydraulics integrated technique, and adopted a new way of network cooperation, broke the overseas technical monopoly, and filled in the blanks of China. It has also opened up a new world market for special engineering equipment, such as high-speed railways, bridges, ships, and wind power. Qingdao Red Collar Group Co., Ltd. adapted to the personalized demand. Its design introduced a new business mode of digital network intelligent garment manufacturing service, which is digital, networked, and intellectual, sales and profits continued to rise, and it became the provider of digital, network and customized production and service system solutions, also became the model for the traditional industries which are undergoing transformation.

\subsection{New concept and new ideas can design and create new needs, reshaping the new market pattern}

Bill Gates first realized the value of software and founded Microsoft. He led a team that designed and developed Windows and Office, bringing PC to everyone. Jobs creatively designed an intelligent mobile terminal of the networking age and developed a new way of co-creating the application software with APP Store and reshaped the market pattern of consumption and service with electronic products, which has changed the way people live and socialize. Ma realized the potential of online business and that integrity is the foundation of China's online business development. He laid the foundation of his success in Ali and Ant Financial Services Group by leading the design of Ali's credit system and the Internet credit big data, largely contributing to the development of China's information network economy and the construction of a commercial credit culture.

\subsection{Design and creation lead the progress of social civilization}

The British designed and created steam engines, working machines, trains, and ships, leading the modern industrial civilization marked by mechanization. The German and American led the modern civilization marked by electrification and automation by designing and inventing electric machines, electrical appliances, internal combustion engines, automobiles, and aircrafts The American designed and invented computers, semiconductors, integrated circuits, and numerical control machine tools, leading the progress of human civilization with electronization, digitization and informatization. Cyber-physical-network computing environment, big data, VR/MR, artificial intelligence, and digital subtractive/additive manufacturing create a new environment for innovative design and bring new powers. People will design and create intellectual products, intelligent manufacturing, new formats of network operation services, and new industries, leading the knowledge network civilization. According 
to the historical experience, the enterprises that own innovative design lead the business, while countries that own innovative design lead the world. Creating values for customers, enterprises, and society, as well as protecting the ecological environment and building a better future, are the everlasting pursuit of innovative design.

\section{Improving the ability of independent innovative design}

In 2010, China surpassed the US in scale of manufacturing industry and became one of the great powers in manufacturing. China have achieved remarkable success in manned spacecraft, supercomputer, high-speed railway, BeiDou Navigation Satellite System, and Y-20 transport aircraft. Manufacturing enterprises with international innovative competitiveness, such as Huawei, Lenovo, Gree, China Railway Engineering Corporation, Hengtong optic-electric, BYD auto, and DJI-Innovations, have risen. However, as a whole, the manufacturing industry in China is large but not strong due to its extensive development mode, low level of informatization, scarcity of core technology, weakness of innovative design capabilities, and surplus of low-end backward production. Regarding import-based facilities, such as key basic materials, components and parts, and high-end equipment, low resource and energy utilization, low value-added rate of manufacturing services, China is still at the mid-low end of the global manufacturing industry chain. With the increasing domestic factors cost, China's traditional competitive advantage is gradually weakening. The world has already entered an age of knowledge network; the technological innovation of information network, clean sustainable energy, new material, green intelligent manufacturing and biological medicine are the key of a new industrial revolution that is gradually developing; big data with information knowledge is becoming the most important innovative resource that can be created together and shared. Germany announced the Industry 4.0 strategy while the U.S. promoted "Industry Internet" and Japan develops synergistic robot and intelligent factory at the same time. The next five to ten years will be a critical period for China to fully implement the Made in China 2025 strategy. China will be upgrading its manufacturing structure, shifting driving forces for development, and deepening the supply-side structural reform, becoming one of the strongest manufacturing powers in the world. China will meet new opportunities for a historic intersection, including the change in world's technology, industrial innovation, and China's economic development transition. Meanwhile, China has to respond to the challenge of the competition between high-end manufacturing revitalization in developed countries and low-cost manufacturing in developing countries. As China accelerates the improvement of infrastructure construction and quality, it must focus on innovation as a driving force, to make breakthroughs in core technologies, improve innovative design ability, and promote the tran- sition of Made in China toward Created in China, Chinese speed toward Chinese quality, and Chinese products toward Chinese brands. Innovative design was developed from traditional design and modern design, which will lead the green intelligent manufacturing service. To carry out innovative design engineering, it is paramount to renew concepts, optimize the environment, boost the construction of basic infrastructure, reform the art design education, and build a design culture; thus, the international competitiveness of Chinese Design, the sustainable development capacity, and the ability to lead the world will be enhanced.

\subsection{Concept renewing}

We must be fully aware that innovative design is playing a leading role in products, technology and operating services. It is a crucial link in many aspects such as advancing the ability of its independence and innovation, also taking a leading position instead of imitation and becoming a strong technology and manufacturing power in the world. It must be guided by developing the new concept of "creative, harmonious, green, open, and sharing", following the rules and seizing the elements of innovation design, recognizing the new features of the age of knowledge network, freeing our minds, seeking truth and being pragmatic, making concerted effort improve the development, leading " $\mathrm{Chi}$ na Design" to be demand oriented, and to be the design of both the world and the future, committing to high-quality and highend design. While enhancing substantial improvement in quality and promoting efficiency and green intelligent manufacturing, we should encourage more design and creation of world-leading products, technology, equipment, and operation services.

\subsection{Environment improvement}

Innovative design has been included as a part of the plan Made in China 2025, and on this basis, we should develop and implement an executive summary of the innovative design. Further, we should be clear about the development goals such as enhancing innovation design ability, leading the construction of a strong manufacturing power and accelerating the transformation to China Design. We should also be clear about the roadmap of important initiatives and technology. It is necessary to improve the policy and regulatory environments, implement tax reduction and exemption of innovative design products plus deduction of design and development cost, give design enterprise the same preferential tax rate as high-tech enterprises, and apply zero tariff on the import and export of design service. In order to implement an effective incentive policy and legislative guarantee for innovative design, we should effectively protect intellectual property rights, strengthening law enforcement supervision. Based on market-oriented agenda, some reforms and innovation should be applied to mechanism and system involving aspects such as resource allocation, equity participation, and 
design evaluation. It is necessary to optimize the enterprise-led innovative development environment where politics, production, education, utilization, and finance merge together, and the military and civilian units are deeply integrated. The Chinese Academy of Engineering, Chinese Mechanical Engineering Society, industry associations, and the alliances of innovative design industry, et cetera, should play bigger roles in leading and promoting. Through evaluation and selection by China Red Star Design Award, Dragon Design Foundation Award, China and good design cases, and by building design towns, design startup hubs, design parks, in addition to holding design exhibitions and conferences, design competitions and forums, an environment of mass startups and innovation is optimized and developed, and an open, shared, safe, and efficient computing environment that is characterized by a world-class cyber-physical-network can be constructed.

\subsection{Basic development strengthening}

In addition to continuing to increase the investment in research and development of basic and cutting-edge science and technology, and accumulating original knowledge and technology, the country and local government as well as the enterprise, should enhance the investment of innovative design, encourage to set up an innovative design fund, and give more support to startups of innovative design. Training and attracting the design talents whose quality should be improved, and optimizing the knowledge, ability and team structure, should enhance the innovative design talent base. In order to reinforce the market-oriented basic technology support system for innovative design and industrial service platform, we should construct national, regional and professional innovative design research institutes, and technical service centers for small and medium-sized enterprises. Improving self-dependent innovation in design theory and tool, plug-in software, computing method, big data platform, should enhance the level of popularization and resource sharing, and strengthen the digitizing, networking and intelligent design basic. Formulating and adopting advanced international industrial standards, would accelerate the promotion of quality, security and innovation, as well as greenization and internationalization level of China design.

\subsection{Reformation of design education}

Creative concept is the soul of innovative design. The primary task of design education is to guide and establish advanced design concept and values, to foster the participants' scientific spirits, craftsmanship spirit and innovative entrepreneurship. Stimulating the imagination and creativity, as well as cultivating interest, motivation and confidence of creative production and innovative design are much more important than teaching the knowledge and offering an experience. Leading and realizing the new trend of innovative design, exploring more advanced science and technology, gaining and disseminating new humanistic knowledge, creating and applying new technology, as well as pursuing and achieving new dreams are much important than teaching the method of design. The existing design concept comprises predecessors' comprehension and summary of rules and methods of innovative design. Innovative design comes from practice, as well as from the understanding and foresight of market and social needs. Innovative development goes on without end. The design concept teaching should be combined with the discussion and analysis of design cases and the innovative practices. "Design 3.0" needs to integrate new knowledge from science and technology, social economy, arts and humanities and ecological environment, and should incorporate analysis and understanding of the method and computing power of big data However, it is more important to cultivate, attract and gather talents, enhance the ability of constructing the design platform network and industrial ecology which is characterized by cooperation and sharing. Innovative design needs global vision, international advanced concept, knowledge, technology and culture. It is necessary to collect resources of innovative design all over the world, and create an international, diverse, compatible and supportive education environment.

\subsection{Design culture construction}

The characteristics and quality of innovative design are determined by the design culture. In the process of industrialization and modernization, design culture with unique features was formed in deferent industrial countries. As a result of focusing on the input in both of basics and cutting-edge research and development, putting emphasis on promoting capability in science, technology, engineering and mathematics(STEM), respecting and encouraging free exploration and innovative creation, the design culture which is led by innovation was formed in the US. Germany became a strong manufacturing power recognized at a global level, though it had started late. In the global market competition, owing to the typical and unique natural science, mathematics, engineering and vocational education, as well as the advanced industrial standard, the superior and reliable German design and manufacturing culture has taken shape. With their splendid culture and art, France and Italy are associated with a graceful and magnificent design culture quality. Japan formed an exquisite practical design culture due to the national conditions and traditions as well as the global competition. In order to become a manufacturing power with Chinese characteristics, we have to cultivate and construct the advanced design culture, which meets the needs of our times, respects innovation and creation, pursues perfection and excellence, sticks to honest cooperation, and at the same time advocates creating and sharing. 